\title{
Diacylglycerol oil for the metabolic syndrome
} Hidekatsu Yanai*1, Yoshiharu Tomono, Kumie Ito ${ }^{1}$, Nobuyuki Furutani ${ }^{1}$, Hiroshi Yoshida ${ }^{2}$ and Norio Tada ${ }^{1}$ Address: ${ }^{1}$ Department of Internal Medicine, The Jikei University School of Medicine, Chiba, Japan and ${ }^{2}$ Department of Laboratory Medicine, The
Jikei University School of Medicine, Chiba, Japan

Email: Hidekatsu Yanai* - yanaih@jikei.ac.jp; Yoshiharu Tomono - tomono@jikei.ac.jp; Kumie Ito - ito@jikei.ac.jp; Nobuyuki Furutani - furutani@jikei.ac.jp; Hiroshi Yoshida - hyoshida@jikei.ac.jp; Norio Tada - n-tada27@jikei.ac.jp

* Corresponding author

Published: II December 2007

Nutrition Journal 2007, 6:43 doi:10.1 186/1475-289/-6-43
Received: 12 August 2007

Accepted: II December 2007

This article is available from: http://www.nutritionj.com/content/6/1/43

(C) 2007 Yanai et al; licensee BioMed Central Ltd.

This is an Open Access article distributed under the terms of the Creative Commons Attribution License (http://creativecommons.org/licenses/by/2.0), which permits unrestricted use, distribution, and reproduction in any medium, provided the original work is properly cited.

\begin{abstract}
Excess adiposity has been shown to play a crucial role in the development of the metabolic syndrome. The elevated fasting and postprandial triglyceride-rich lipoprotein levels is the central lipid abnormality observed in the metabolic syndrome. Recent studies have indicated that diacylglycerol (DAG) is effective for fasting and postprandial hyperlipidemia and preventing excess adiposity by increasing postprandial energy expenditure. We will here discuss the mechanisms of DAG-mediated improvements in hyperlipidemia and in postprandial energy expenditure, and effects of DAG oil on lipid/glucose metabolism and on body fat. Further, the therapeutic application of DAG for the metabolic syndrome will be considered.
\end{abstract}

\section{Introduction}

Visceral fat accumulation has been shown to play a crucial role in the development of the metabolic syndrome, which is highly atherogenic. Dyslipidemia associated with the metabolic syndrome are elevated fasting and postprandial triglyceride (TG)-rich lipoproteins and decreased high-density lipoprotein (HDL) [1]. Insulin resistance resulting from obesity decreases lipoprotein lipase (LPL) activity, and then, a reduced LPL activity leads to the decreased clearance of fasting and postprandial TG-rich lipoproteins and to the decreased production of HDL [1]. The elevated level of fasting and postprandial TG-rich lipoproteins is the typical lipid abnormality observed in the metabolic syndrome [1].

Diacylglycerol (DAG) oil is present in edible vegetable oils. Recent studies have indicated that DAG is effective for fasting and postprandial hyperlipidemia and for pre- venting excess adiposity [2]. We will here discuss the therapeutic application of DAG for the metabolic syndrome.

\section{Biochemical properties of DAG}

DAG is a natural component of various edible oils (Table 1) $[3,4]$. DAG can be synthesized enzymatically with the reverse reaction of 1,3-specific lipase, and consists mainly of the 1,3-species due to the migration of the acyl group in an equilibrium reaction. The ratio of the 1,3-DAG to 1,2-DAG in DAG oil is approximately 7:3 (Fig. 1) [2].

\section{The mechanism of DAG-mediated} improvement in postprandial hyperlipidemia Dietary TAG oil is hydrolyzed by lipase to free fatty acids (FFA) and 2-monoacylglycerol in the small intestinal lumen, and these are absorbed by intestinal cells (Fig. 2). In intestinal cells, TG is re-synthesized from 2-monoacylglycerol and two FFA via the 2-monoacylglycerol pathway [5]. Monoacylglycerol acyltransferase (MGAT) and dia- 
Table I: Contents (weight \%) of triacylglycerol and diacylglycerol in various edible oils $[3,4]$

\begin{tabular}{lcc}
\hline & Triacylglycerol & Diacylglycerol \\
\hline Soybean oil & 97.9 & 1.0 \\
Cottonseed oil & 87.0 & 9.5 \\
Palm oil & 93.1 & 5.8 \\
Corn oil & 95.8 & 2.8 \\
Safflower oil & 96.0 & 2.1 \\
Olive oil & 93.3 & 5.5 \\
Rapeseed oil & 96.8 & 0.8 \\
Lard & 97.9 & 1.3 \\
\hline
\end{tabular}

cylglycerol acyltransferase (DGAT) work in the 2-monoacylglycerol pathway $[6,7]$. TG is incorporated into chylomicrons (CM) by microsomal triglyceride transfer protein (MTP), which are released into the intestinal lymph and poured into the bloodstream [8].

In the case of DAG oil, the metabolic pathway in the intestinal cells is different from that of TAG oil (Fig. 3). Dietary DAG oil is mainly in the form of 1,3-DAG. 1,3-DAG would be hydrolyzed to initially to 1-monoacylglycerol and then, to glycerol and FFA, which are absorbed into the intestinal cells [9]. TG cannot be synthesized from 1monoacylglycerol via the 2-monoacylglycerol pathway in the intestinal cells, because 1-monoacylglycerol cannot be the substrate for both DGAT and MGAT [6,7]. TG could be synthesized via the glycerol-3-phosphate pathway, which is less active than the 2-monoacylglycerol pathway [10]. 1,2-DAG would be hydrolyzed to 2-monoacylglycerol, and TG is synthesized via the 2-monoacylglycerol pathway [2].

\section{A. Triacylglycerol (TAG) B. Diacylglycerol (DAG)}

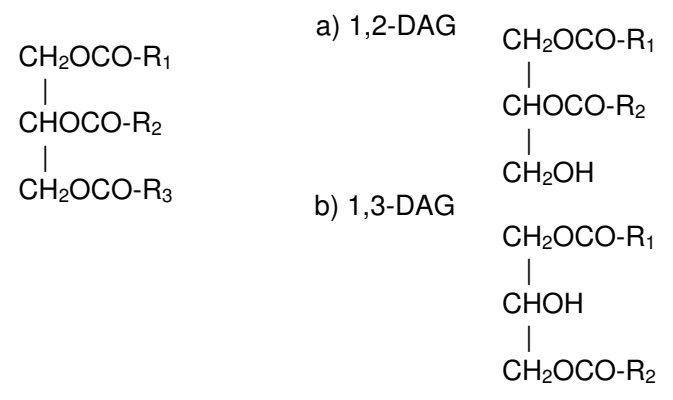

1,2-DAG:1,3-DAG $=3: 7$

\section{Figure I}

Structure of triacylglycerol and diacylglycerol. RI, R2, and R3 indicate fatty acids.
Recently, Yasunaga $\mathrm{K}$, et al found that DAG oil reduced plasma TG levels, resulting from more efficient clearance of DAG by both LPL-mediated lipolysis and apolipoprotein E-mediated hepatic endocytosis [11]. In also SpragueDawley rats, a lower plasma TG levels was accompanied by an increase in adipocyte LPL activity [12].

At present, slower re-acylation to TAG in small intestinal cells, an increase in LPL activity and apolipoprotein Emediated hepatic endocytosis are supposed to be the underlying mechanisms improving the postprandial hyperlipidemia by substitution of DAG for TAG ingestion.

\section{Effects of DAG oil on lipid and glucose metabolism}

An outline of reported effects of DAG on lipid/glucose metabolism is shown in Table 2. In animals, DAG ingestion was demonstrated to reduce plasma TG and FFA levels compared with TAG ingestion. Fujii A, et al found that DAG-rich oil reduced atherosclerosis in diabetic apoEdeficient mice, and ingestion of DAG-rich oil was associated with reduction in plasma cholesterol levels within larger TG-rich lipoproteins [13]. Further, DAG ingestion was reported to prevent the high-sucrose-diet-induced development of impaired glucose tolerance compared with TAG oil ingestion, in male Wistar rats [14].

In our previous studies with healthy volunteers, serum TG and remnant-like lipoprotein particles-cholesterol (RLPC) concentrations after DAG ingestion were significantly lower than those after TAG ingestion [15]. Tomonobu $\mathrm{K}$, et al. also reported that postprandial TG, RLP-C, and CMTG concentrations were significantly lower after DAG ingestion than after TAG ingestion [16]. In our study with diabetic patients, DAG loading significantly suppressed increases in postprandial serum TG, RLP-C and RLP-TG levels as compared with TAG loading [17].

Recent study found that DAG reduced postprandial increase in TG, RLP-C, and RLP-TG, especially in subjects with insulin resistance [18]. In the subjects who consumed daily $10 \mathrm{~g}$ of DAG for 12 weeks, serum TG levels were decreased by $39.4 \%$, and serum hemoglobin A1c levels were also decreased by $9.7 \%$, compared with subjects who consumed TAG, suggesting that DAG ingestion also ameliorates glucose metabolism [19]. Further, a longterm DAG oil consumption has been reported to increase HDL-C, and decrease fasting TG, total cholesterol, LDL-C, compared with TAG consumption [20-22].

The apolipoprotein C-II is a cofactor of LPL, which hydrolyzes TG of CM and very-low-density lipoprotein (VLDL) [23]. We have a therapeutic experience with DAG oil to a patient with apolipoprotein C-II deficiency, a rare autosomal recessively-inherited disease [24]. In a patient with 


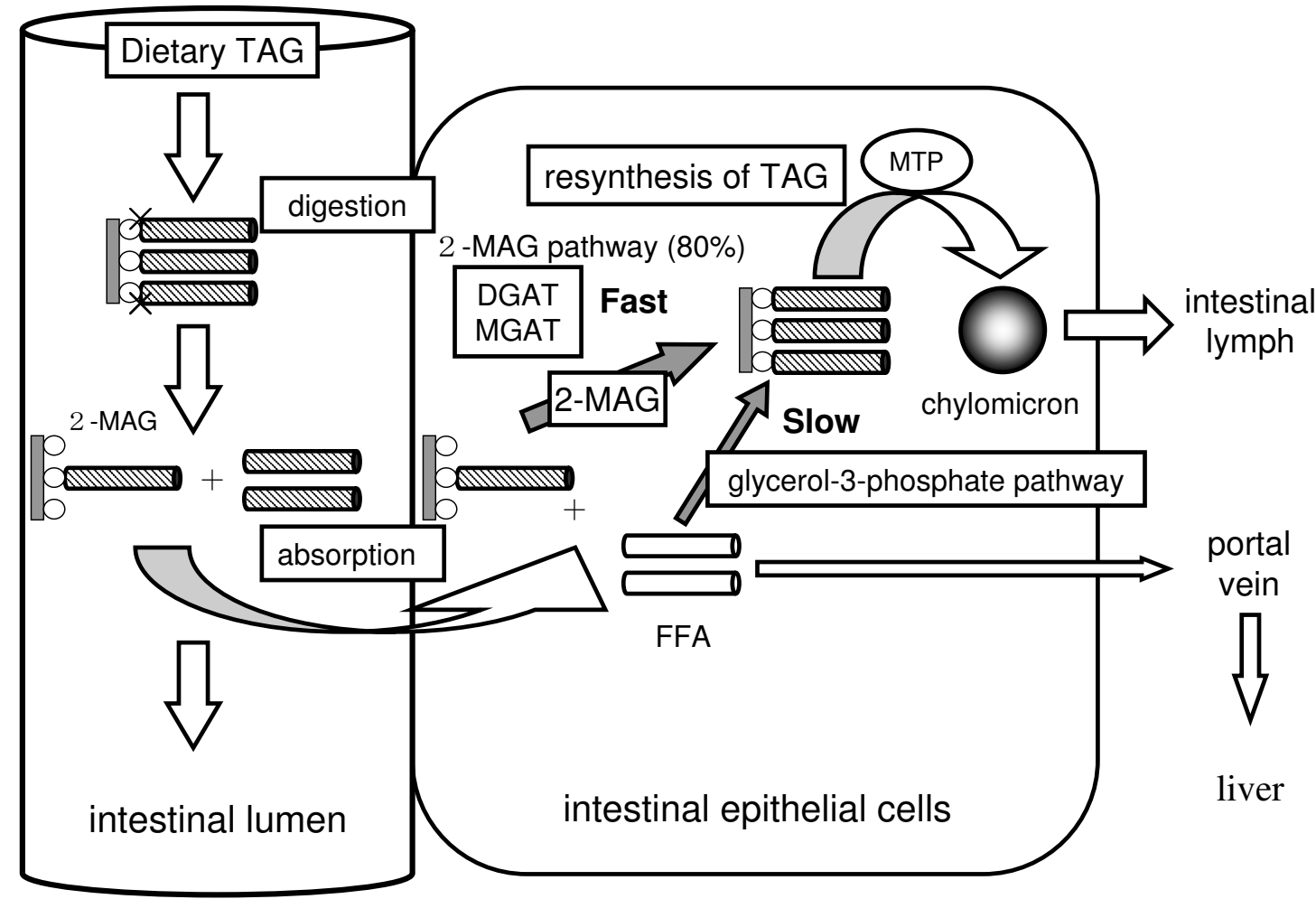

\section{Figure 2}

Digestion and absorption of triacylglycerol. DGAT, diacylglycerol acyltransferase; FFA, free fatty acids; 2-MAG, 2-monoacylglycerol; MGAT, monoacylglycerol acyltransferase; MTP, microsomal triglyceride transfer protein; TAG, triacylglycerol.

apolipoprotein C-II deficiency, DAG ingestion suppressed increase in serum TG, VLDL-C, and RLP-C levels compared with TAG ingestion, suggesting that DAG can decrease TG-rich lipoprotein, also independent of LPL.

In summary, DAG ameliorates fasting and postprandial TG-rich lipoproteins, and glucose metabolism, which may be favorable for metabolic disorders observed in the metabolic syndrome.

\section{The mechanism to promote negative caloric balance by DAG ingestion}

Compared with the TAG-containing meal, the DAG-containing meal tended to induce higher postprandial energy expenditure and significantly lower postprandial respiratory quotient, suggesting that the DAG-containing meal has high postprandial lipid oxidation activity and a poten- tial effect on high diet-induced thermogenesis $[25,26]$. Upregulated mRNA expressions associated with FA transport (FA translocase and FA binding protein), $\beta$-oxidation (acyl-CoA oxidase and medium-chain acyl-CoA dehydrogenase), and thermogenesis (uncoupling protein-2) in the small intestine by DAG may explain in part mechanisms for increased postprandial energy expenditure $[27,28]$.

\section{Effect of a long-term consumption of dietary DAG for adiposity}

An outline of a long-term effect of DAG ingestion on body composition is shown in Table 3. In rats, DAG-rich oil ingestion was effective in suppressing FA synthase activity and enhancing $\beta$-oxidation activity, reducing the abdominal fat [29]. In brown adipose tissue-deficient mice, a model of high-fat diet-induced insulin resistance and obesity, a long term substitution of DAG for TAG reduced 


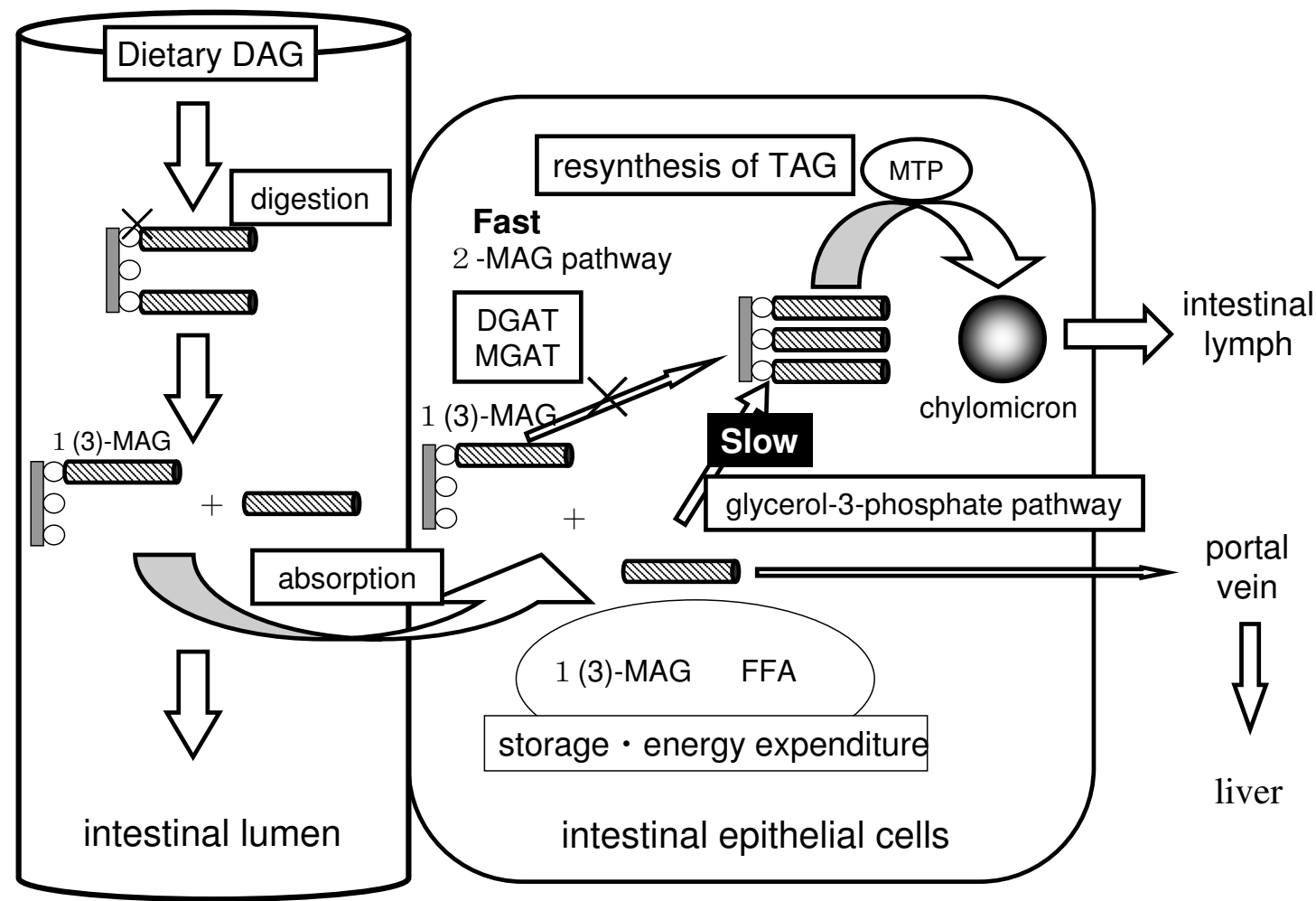

\section{Figure 3}

Digestion and absorption of diacylglycerol. DGAT, diacylglycerol acyltransferase; FFA, free fatty acids; I(3)-MAG, I-monoacylglycerol or 3-monoacylglycerol; MGAT, monoacylglycerol acyltransferase; MTP, microsomal triglyceride transfer protein; TAG, triacylglycerol.

Western-type diets induced insulin resistance and body fat accumulation by suppressing hepatic gluconeogenesis and stimulating fat oxidation in skeletal muscle [30].

A long-term consumption of DAG decreased body fat, especially visceral fat, and decreased body weight in both overweight and normal Japanese people, and obese subjects in the United States, compared with TAG consumption [31-33]. Open-labeled long-term consumption study indicated that DAG decreased body weight compared with TAG consumption [20]. In several long-term studies, decrease in waist circumferences and skin fold thickness by DAG consumption were observed [21,22,33].

Thus, several long-term clinical trials have indicated that DAG consumption results in losses of body weight and body fat, in healthy non-obese and obese men and women. Further, DAG oil ingestion decreased both the abdominal fat area and leptin in obese children, suggesting that DAG oil prevents excess adiposity in children as well as in adults [34]. Dairy ingestion of 8-20 g DAG has been used in human studies on the effect of DAG on body composition [35]. However, it remains unknown how dose DAG is high effective for preventing excess adiposity, which should be investigated in the future.

In summary, DAG may be beneficial in preventing excess adiposity, which may be favorable for the metabolic syndrome.

\section{A safety of a chronic consumption of DAG}

In c-Ha-ras proto-oncogene transgenic rats, DAG oil administration was associated with a significant increase in the incidence of squamous cell carcinomas of the tongue with the Cochran-Armitage trend test and also number of tumors in coefficients for linear contrast trend 
Table 2: Effects of DAG on lipid and glucose metabolism

fasting serum lipids $[20,21,22]$

$\downarrow$ triglyceride

$\uparrow$ high-density lipoprotein cholesterol

$\downarrow$ total cholesterol

$\downarrow$ low-density lipoprotein cholesterol

postprandial serum lipids $[15,16,17]$

$\downarrow$ triglyceride

$\downarrow$ remnant-like lipoprotein particle triglyceride

$\downarrow$ remnant-like lipoprotein particle cholesterol

$\downarrow$ chylomicron triglyceride

glucose metabolism [19]

$\downarrow$ hemoglobin Alc

Table 3: A long-term effect of DAG ingestion on body composition $[20,21,22,31,32,33]$

$\downarrow$ body weight
$\downarrow$ body fat
$\downarrow$ Visceral fat
$\downarrow$ Subcutaneous fat
$\downarrow$ hepatic fat
$\downarrow$ Waist circumferences
$\downarrow$ Skin fold thickness

tests [36]. However, 24 months-DAG-treated rats had no higher risk of carcinogenic effects than rats fed on similar feeding regimens with TAG [37]. The potential chronic toxic effects of DAG when administered orally for 12 months were evaluated using Beagle dogs [38]. DAG at dietary concentrations up to $9.5 \%$ for one year had no effect on normal dog growth and development, in comparison to TAG [38]. In mice, DAG at dietary concentrations up to $6.0 \%$ for 24 months produced no signs of systemic toxicity and had no effect on the incidence of neoplastic findings [39]. Most of studies investigating a chronic dietary toxicity of DAG reported that DAG did not produce systemic toxicity and had no effect on the incidence of neoplastic findings. However, we should observe the safety of a chronic consumption of DAG carefully.

\section{Conclusion}

DAG oil consumption has been reported to ameliorate the constituents of the metabolic syndrome such as excess adiposity, impaired glucose metabolism, and dyslipidemia, suggesting the usefulness of DAG oil for the management and prevention of the metabolic syndrome.

\section{References}

I. Ruotolo G, Howard BV: Dyslipidemia of the metabolic syndrome. Curr Cardiol Rep 2002, 4:494-500.

2. Tada N: Physiological actions of diacylglycerol outcome. Curr Opin Clin Nutr Metab Care 2004, 7: I45-I49.

3. Abdel-Nabey AA, Shehata Y, Ragab MH, Rossell JB: Glycerides of cottonseed oils from Egyptian and other varieties. Riv ltal Sostanze Grasse 1992, 69:443-447.

4. D'alonzo RP, Kozarek WJ, Wade RL: Glyceride composition of processed fats and oils as determined by glass capillary gas chromatography. J Am Oil Chem Soc 1982, 59:292-295.

5. Yang LY, Kuksis A: Apparent convergence (at 2-monoacylglycerol level) of phosphatidic acid and 2-monoacylglycerol pathways of synthesis of chylomicron triacylglycerols. J Lipid Res 199|, 32: II73-II86.

6. Cao J, Lockwood J, Burn P, Shi Y: Cloning and functional characterization of a mouse intestinal acyl-CoA:monoacylglycerol acyltransferase, MGAT2. J Biol Chem 2003, 278: I3860-I3866.

7. Cheng D, Nelson TC, Chen J, Walker SG, Wardwell-Swanson J, Meegalla R, Taub R, Billheimer JT, Ramaker M, Feder JN: Identification of acyl coenzyme A:monoacylglycerol acyltransferase 3, an intestinal specific enzyme implicated in dietary fat absorption. J Biol Chem 2003, 278: I36II-136I4.

8. White DA, Bennett AJ, Billett MA, Salter AM: The assembly of triacylglycerol-rich lipoproteins: an essential role for the microsomal triacylglycerol transfer protein. Br J Nutr 1998, 80:219-229.

9. Watanabe $\mathrm{H}$, Onizawa $\mathrm{K}$, Taguchi $\mathrm{H}$, Kobori M, Chiba $\mathrm{H}$, Naito $\mathrm{S}$, Matsuno N, Yasukawa T, Hattori M, Shimasaki H: Nutritional characterization of diacylglkycerols in rats (in Japanese). J Jpn Oil Chem Soc 1997, 46:301-307.

10. Friedman $\mathrm{HI}$, Nylund B: Intestinal fat digestion, absorption, and transport. Am J Clin Nutr 1980, 33: I I08-I I39.

II. Yasunaga K, Saito S, Zhang YL, Hernandez-Ono A, Ginsberg HN: Effects of triacylglycerol and diacylglycerol oils on blood clearance, tissue uptake, and hepatic apolipoprotein B secretion in mice. J Lipid Res 2007, 48: I I08-I I2I.

12. Kim HJ, Lee KT, Lee MK, Jeon SM, Jung UJ, Cho YY, Choi MS: Hypolipidemic effect of dietary diacylglycerol oil in Sprague-Dawley rats fed a normal diet. J Med Food 2007, 10:60-66.

13. Fujii A, Allen TJ, Nestel PJ: A I,3-diacylglycerol-rich oil induces less atherosclerosis and lowers plasma cholesterol in diabetic apoE-deficient mice. Atherosclerosis 2007, 193:55-61.

14. Meguro S, Osaki N, Matsuo N, Tokimitsu I: Effect of diacylglycerol on the development of impaired glucose tolerance in sucrose-fed rats. Lipids 2006, $41: 347-355$.

15. Tada N, Watanabe H, Matsuo N, Tokimitsu I, Okazaki M: Dynamics of postprandial remnant-like lipoprotein particles in serum after loading of diacylglycerols. Clin Chim Acta 200I, 3II:109-117.

16. Tomonobu K, Hase T, Tokimitsu I: Dietary diacylglycerol in a typical meal suppresses postprandial increases in serum lipid levels compared with dietary triacylglycerol. Nutrition 2006, 22: $128-135$.

17. Tada N, Shoji K, Takeshita M, Watanabe H, Yoshida H, Hase T, Matsuo $\mathrm{N}$, Tokimitsu I: Effects of diacylglycerol ingestion on postprandial hyperlipidemia in diabetes. Clin Chim Acta 2005, 353:87-94.

18. Takase H, Shoji K, Hase T, Tokimitsu I: Effect of diacylglycerol on postprandial lipid metabolism in non-diabetic subjects with and without insulin resistance. Atherosclerosis 2005, 180:197-204.

19. Yamamoto K, Asakawa H, Tokunaga K, Watanabe H, Matsuo N, Tokimitsu I, Yagi N: Long-term ingestion of dietary diacylglycerol lowers serum triacylglycerol in type II diabetic patients with hypertriglyceridemia. J Nutr 200 I, I 3 I:3204-3207.

20. Yasukawa T, Yasunaga K: Nutritional functions of dietary diacylglycerols. J Oleo Sci 200 I, 50:427-432.

21. Katsuragi $Y$, Toi T, Yasukawa T: Effects of dietary diacylglycerols on obesity and hyperlipidemia. J Jpn Hum Dry Dock 1999, 14:258-262.

22. Otsuki K, Mori K, Onodera Y: Final report from two-year intervention using edible oil rich in diacylglycerol. 44th Annual Meeting of the Japanese Society of Human Dry Dock, Kyoto 2003:27-29. 
23. Breckenridge WC, Alaupovic P, Cox DW, Little JA: Apolipoprotein and lipoprotein concentrations in familial apolipoprotein $C$ II deficiency. Atherosclerosis 1982, 44:223-235.

24. Yanai $\mathrm{H}$, Tada N, Yoshida $\mathrm{H}$, Tomono $\mathrm{Y}$ : Diacylglycerol oil for apolipoprotein C-II deficiency. QJM 2007, 100:247-248.

25. Kimura S, Tsuchiya H, Inage H, Meguro S, Matsuo N, Tokimitsu I: Effects of dietary diacylglycerol on the energy metabolism. Int J Vitam Nutr Res 2006, 76:75-79.

26. Saito S, Tomonobu K, Hase T, Tokimitsu I: Effects of diacylglycerol on postprandial energy expenditure and respiratory quotient in healthy subjects. Nutrition 2006, 22:30-35.

27. Murase T, Nagasawa A, Suzuki J, Wakisaka T, Hase T, Tokimitsu I: Dietary alpha-linolenic acid-rich diacylglycerols reduce body weight gain accompanying the stimulation of intestinal betaoxidation and related gene expressions in C57BL/KsJ-db/db mice. J Nutr 2002, 132:3018-3022.

28. Murase T, Aoki M, Wakisaka T, Hase T, Tokimitsu I: Anti-obesity effect of dietary diacylglycerol in C57BL/6J mice: dietary diacylglycerol stimulates intestinal lipid metabolism. J Lipid Res 2002, 43: $1312-1319$.

29. Kim HJ, Lee KT, Lee MK, Jeon SM, Choi MS: Diacylglycerolenriched structured lipids containing CLA and capric acid alter body fat mass and lipid metabolism in rats. Ann Nutr Metab 2006, 50:219-228.

30. Saito S, Hernandez-Ono A, Ginsberg HN: Dietary I,3-diacylglycerol protects against diet-induced obesity and insulin resistance. Metabolism 2007, 56: I566-I575.

3I. Maki KC, Davidson MH, Tsushima R, Matsuo N, Tokimitsu I, Umporowicz DM, Dicklin MR, Foster GS, Ingram KA, Anderson BD, Frost $\mathrm{SD}$, Bell M: Consumption of diacylglycerol oil as part of a reduced-energy diet enhances loss of body weight and fat in comparison with consumption of a triacylglycerol contro oil. Am J Clin Nutr 2002, 76:1230-I 236.

32. Nagao T, Watanabe H, Goto N, Onizawa K, Taguchi H, Matsuo N, Yasukawa T, Tsushima R, Shimasaki H, Itakura H: Dietary diacylglycerol suppresses accumulation of body fat compared to triacylglycerol in men in a double-blind controlled trial. J Nutr 2000, 130:792-797.

33. Koyama W: Long-term effects of diacylglycerol used as libitum as cooking oil in home. 24th Annual Meeting of Japan Society for the Study of Obesity, Chiba 2003:13-14.

34. Matsuyama T, Shoji K, Watanabe H, Shimizu M, Saotome Y, Nagao T, Matsuo N, Hase T, Tokimitsu I, Nakaya N: Effects of diacylglycerol oil on adiposity in obese children: initial communication. J Pediatr Endocrinol Metab 2006, 19:795-804.

35. Rudkowska I, Roynette CE, Demonty I, Vanstone CA, Jew S, Jones PJ: Diacylglycerol: efficacy and mechanism of action of an antiobesity agent. Obes Res 2005, 13:1864-1876.

36. Tsuda $\mathrm{H}$, ligo M, Takasuka N, Ueda S, Ohshima Y, Fukamachi K, Shirai T, Hirano S, Matsuda E, Wakabayashi K: Possible enhancing activity of diacylglycerol on 4-nitroquinoline I-oxide induced carcinogenesis of the tongue in human c-Ha-ras protooncogene transgenic rats. Food Chem Toxicol 2007, 45: I0 I3-10I9.

37. Chengelis $\mathrm{CP}$, Kirkpatrick JB, Bruner RH, Freshwater L, Morita $\mathrm{O}$, Tamaki Y, Suzuki H: A 24-month dietary carcinogenicity study of DAG (diacylglycerol) in rats. Food Chem Toxicol 2006 44:98-12I.

38. Chengelis CP, Kirkpatrick JB, Marit GB, Morita O, Tamaki Y, Suzuki $\mathrm{H}$ : A chronic dietary toxicity study of DAG (diacylglycerol) in Beagle dogs. Food Chem Toxicol 2006, 44:8I-97.

39. Chengelis CP, Kirkpatrick JB, Bruner RH, Freshwater L, Morita $O$ Tamaki Y, Suzuki H: A 24-month dietary carcinogenicity study of DAG in mice. Food Chem Toxicol 2006, 44:122-137.
Publish with Biomed Central and every scientist can read your work free of charge

"BioMed Central will be the most significant development for disseminating the results of biomedical research in our lifetime. "

Sir Paul Nurse, Cancer Research UK

Your research papers will be:

- available free of charge to the entire biomedical community

- peer reviewed and published immediately upon acceptance

- cited in PubMed and archived on PubMed Central

- yours - you keep the copyright

Submit your manuscript here:

http://www.biomedcentral.com/info/publishing_adv.asp
BioMedcentral 